\title{
The Decision of Fatigue State Based On Characteristics' Fuzzy Fusion
}

\author{
Guozhen $\mathrm{Cao}^{1, \text { a }}$, Han Peng ${ }^{2}$ \\ ${ }^{1}$ Xi'an Aviation Academy, Xi'an, 710077, China; \\ ${ }^{2}$ School of computer science, Northwestern Polytechnical University, Xi'an, 710072, China \\ a411406477@qq.com
}

\begin{abstract}
The fatigue recognition process based on visual, using a single feature to fatigue driving, often by the universal applicability, the influence of factors such as noise, leading to the recognition rate is reduced. Characteristic parameters in order to solve the eye or mouth feature parameters of the individual character recognition rate is low and even envoy environment cannot be any other questions, this paper proposes a decision method based on feature fusion, using a variety of characteristics between the complementary advantages, can reduce the effects of difference between noise and class in the class, so as to improve the performance of the system, and can enhance the applicability. Finally, the experimental results show that using the eye and mouth features fusion method is higher accuracy than a single sentence.
\end{abstract}

Keywords: Fuzzy controller; Eye feature parameters; Mouth characteristic parameters.

\section{Introduction}

With the development of science and technology, car ownership is also increasing, the high incidence of road traffic accidents in China, 2012, 2013, 2014, the number of deaths were 30222, 31604, 34292[1]. Klauer [2] and other research found that the probability of fatigue driving traffic accidents is 46 times the normal driving. According to the United States NHTSA related research shows that every year due to fatigue driving and traffic accidents caused by at least 100 thousand from [3]. In China, each year due to fatigue driving caused by the total accident rate, the accident rate, the death rate of $20 \%$, more than $40 \%, 83 \%$ [4]. Although the proportion of fatigue driving caused by traffic accidents in different countries, there are some differences, but the basic is about $20 \%$ [5]. Method of driving fatigue judgment based on individual characteristics, often influenced by non-general applicability, noise and other factors, so as to reduce the recognition rate, so we proposed a detection method of fatigue driving method based on fuzzy logic.

\section{Fatigue driving fuzzy controller design}

Yawning is fatigue or when the body's lack of sleep performance, while in the state of fatigue, the characteristics of the eye area will be a significant change. This paper uses two fuzzy controller combination to fatigue judgment, firstly to extract the average blink frequency and duration of these two parameters using fuzzy logic method of feature fusion, obtain the eye state, and then input to state together with the mouth of eye and mouth fuzzy controller, the fatigue (final judgment as shown in Figure 1).

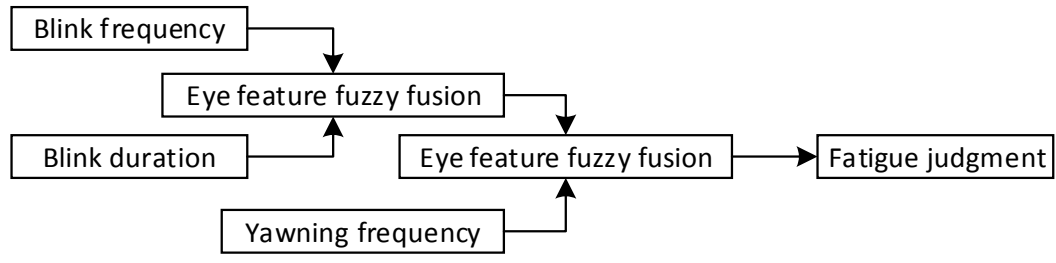

Fig. 1 fuzzy fusion decision

\subsection{The establishment of membership function}

For the eye feature fuzzy controller, the blink frequency and duration are defined as two inputs and one output variable respectively. The output of the eye fatigue state and the mouth yawning state is 
used as the input of the fuzzy controller two (i.e., the eye mouth fuzzy fusion) by using the fuzzy controller (i.e., the eye feature fuzzy fusion).

Fuzzy controller with two input for the eyes and mouth fatigue fatigue, the output for the final fatigue, membership function respectively: eye fatigue $=\{$ is awake, awake, fatigue, fatigue, attention is $\}=\{\mathrm{NB}, \mathrm{NS}, \mathrm{Z}, \mathrm{PS}, \mathrm{PB}\}, \mathrm{NB}=\left[\begin{array}{lll}0.1 & 0 & 0.3\end{array}\right], \mathrm{NS}=\left[\begin{array}{lll}0 & 0.3 & 0.6\end{array}\right], \mathrm{Z}=\left[\begin{array}{lll}0.3 & 0.6 & 0.9\end{array}\right] \mathrm{PS}=\left[\begin{array}{ll}0.6,0.9 & 1.2\end{array}\right], 1.2$ $\mathrm{PB}=[0.92]$; the frequency of yawning $=\{$ fast, fast, slow, $\}=\{\mathrm{PB}, \mathrm{Ps}, \mathrm{Z}, \mathrm{NB}\}, \mathrm{NB}=\left[\begin{array}{ll}0.1 & 0\end{array}\right], \mathrm{NS}=\left[\begin{array}{ll}0 & 2\end{array}\right]$, $\mathrm{Z}=\left[\begin{array}{lll}2 & 4 & 6\end{array}\right], \mathrm{PB}=\left[\begin{array}{lll}4 & 620 & 24\end{array}\right]$ output; fatigue $=\{$ sober, sober, attention, fatigue, fatigue compared to $\}=\{\mathrm{NB}, \mathrm{NS} . \mathrm{Z}, \mathrm{PS}, \mathrm{PB}\}, \mathrm{NB}=\left[\begin{array}{lll}0.1 & 0 & 0.3\end{array}\right], \mathrm{NS}=\left[\begin{array}{lll}0 & 0.3 & 0.6\end{array}\right], \mathrm{Z}=\left[\begin{array}{lll}0.3 & 0.6 & 0.9\end{array}\right], \mathrm{PS}=\left[\begin{array}{lll}0.6 & 0.9 & 1.2\end{array}\right], \mathrm{PB}=$ [ $\left.\begin{array}{ll}0.9 & 1.2\end{array}\right]$, when the final output is greater than or equal to 0.8 is judged as fatigue, otherwise the normal state.

\subsection{The establishment of fuzzy inference rules}

The establishment of fuzzy control rules is very important, whether the rules can correctly reflect the experience and knowledge of the operators and the relevant experts, and directly related to the performance and effectiveness of the control. For a fuzzy controller, a maximum of 25 control rules can be obtained from each other, which can be controlled by a simple fuzzy control rule table, as shown in Table 1. For the two input variables of fuzzy controller, the fatigue state of the eye and the fatigue state of the mouth, the 20 control rules can be obtained at most, and the 20 control rules of inference are shown in Table 2.

Table 1 Fuzzy control rule table

\begin{tabular}{|c|c|c|c|c|c|}
\hline \multirow{2}{*}{ Blink frequency } & \multicolumn{5}{|c|}{ Average blink duration } \\
\hline & NB & NS & $\mathrm{Z}$ & PS & $\mathrm{PB}$ \\
\hline NB & NB & NB & $\mathrm{NZ}$ & $\mathrm{Z}$ & $\mathrm{PB}$ \\
\hline NS & NB & NS & $\mathrm{Z}$ & PS & PB \\
\hline $\mathrm{Z}$ & NS & $\mathrm{Z}$ & PS & $\mathrm{PB}$ & PB \\
\hline PS & $\mathrm{Z}$ & PS & PB & PB & PB \\
\hline $\mathrm{PB}$ & PS & PS & PB & $\mathrm{PB}$ & PB \\
\hline \multicolumn{6}{|c|}{ Table 2 Control rule table } \\
\hline Yawning & \multicolumn{5}{|c|}{ Eye condition } \\
\hline frequency & NB & NS & $\mathrm{Z}$ & PS & PB \\
\hline NB & NB & NB & $\mathrm{Z}$ & PS & PB \\
\hline $\mathrm{Z}$ & NB & NS & $\mathrm{Z}$ & PS & $\mathrm{PB}$ \\
\hline PS & NS & $\mathrm{Z}$ & PS & PB & PB \\
\hline PB & $\mathrm{Z}$ & PS & $\mathrm{PB}$ & PB & $\mathrm{PB}$ \\
\hline
\end{tabular}

\section{The overall design of fatigue driving detection algorithm}

Fatigue driving test process as shown in Figure 2. Feature positioning for the positioning of the human eye and mouth and to seek its aspect ratio, parameters extracted to extract the frame of the first 1 minutes of the blink frequency, the average blink duration and yawning frequency. The first face detection for the first frame image, determine the face region, in the frame of the face region tracking, only in tracking failure within the parameters, so in the beginning of the 120 frame is not within the parameters extraction, just extract the aspect ratio of each frame of the eyes and mouth, and get in the 120 frame the aspect ratio of the maximum and minimum value; when the 120 frame processing is completed, in the subsequent frames of the frame can be 1 minutes before the blink frequency and other parameters are extracted, and determine the fatigue. 


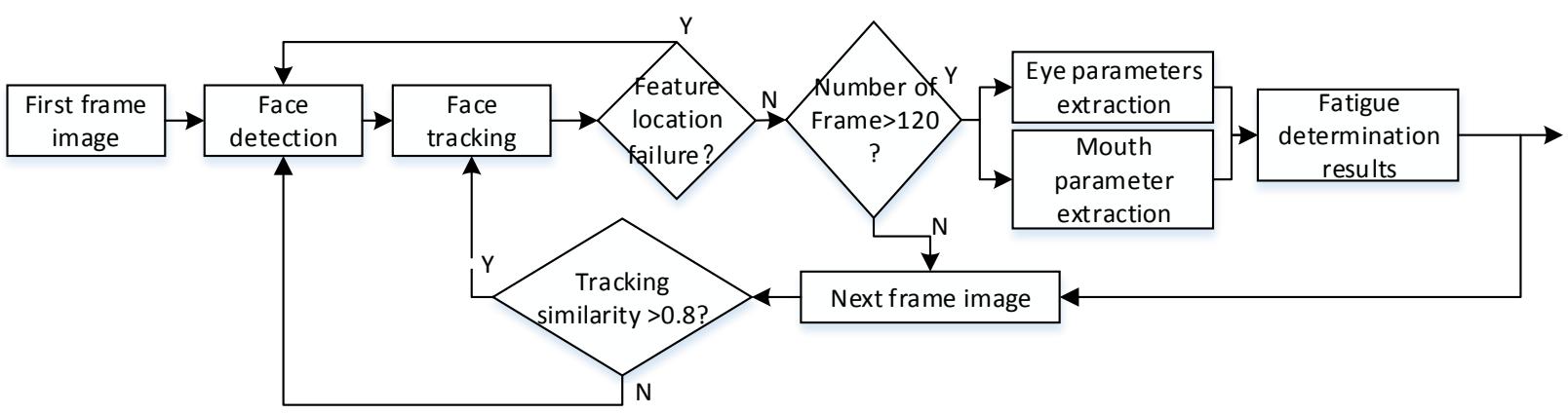

Fig. 2 Total flow chart of fatigue driving test

After obtaining the parameters such as the blink frequency, average blink duration and yawning frequency, we can use the fuzzy fusion method established in this paper to determine the degree of fatigue, and the fatigue judgment flow chart is shown in Figure 3. Firstly, blink frequency and average blink duration fuzzy controller based on fuzzy input membership function, fuzzy reasoning, combined with the output membership function for defuzzification, the fatigue state of eyes; then the eye fatigue and yawning frequency as input, through the fuzzy controller two obtains the final fatigue, determination whether fatigue driving.

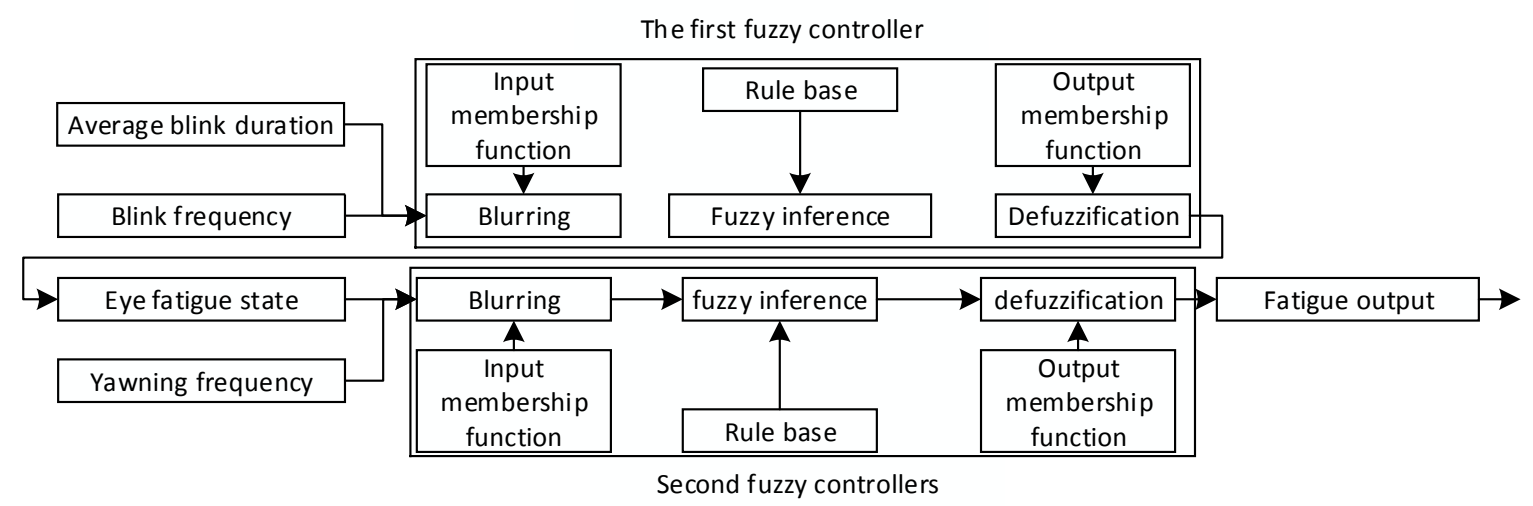

Fig. 3 fuzzy controller

\section{Test analysis}

Select 20 groups of image sequences in laboratory simulation of drive fatigue tests carried out, in which 1-5 group containing yawn action and eye fatigue degree is high, 6-10 group without yawning action but higher eye fatigue, 11-15 group containing yawn action but eye fatigue degree is low, the 16-20 group without yawning action and eye fatigue degree is low, the image size is $320 \times 240,20$ frames per second, respectively using A: eye state determination (using blink frequency and average blink duration), B: mouth state determination (using the frequency of yawning), C: mouth state determination of eye state detection, then $\mathrm{D}$ : eyes and mouth fusion decision four methods to judge the fatigue experimental results, as shown in Table 3, table 3 fatigue with Y said, not fatigue $\mathrm{N}$.

Table 3 shows the use of a method in group 3, 4, 6, 7, 12, 15, 20 misjudgment, use the B method in group 8, 9, 10, 11, 13, 14 misjudgment, and use the $C$ method in group 6, 7, 11, 13, 14 false positives. From the experimental results, it can be seen that the joint use of eye and mouth than the use of a single feature in the accuracy of the fatigue judgment has significantly improved. Detection of video sequences and different driver fatigue fatigue state, each video sequence is 3 minutes long, test results show that the correct rate of the algorithm proposed in this paper is in the head deflection fatigue test was $93.6 \%$, when the head deflection, the correct rate is $87.9 \%$ which shows that the detection rate of this algorithm is high. 
Table 3 test results

\begin{tabular}{|c|c|c|c|c|c|c|c|c|c|}
\hline \multirow{2}{*}{ Group } & \multicolumn{4}{|c|}{ selection method } & \multirow{2}{*}{ Group } & \multicolumn{4}{|c|}{ selection method } \\
\hline & A & $\mathrm{B}$ & $\mathrm{C}$ & $\mathrm{D}$ & & A & $\mathrm{B}$ & $\mathrm{C}$ & $\mathrm{D}$ \\
\hline 1 & $\mathrm{Y}$ & $\mathrm{Y}$ & $\bar{Y}$ & $\mathrm{Y}$ & 11 & $\mathrm{~N}$ & $\mathrm{Y}$ & $\mathrm{Y}$ & $\mathrm{N}$ \\
\hline 2 & $\mathrm{Y}$ & Y & $\mathrm{Y}$ & Y & 12 & $\mathrm{~N}$ & Y & $\mathrm{Y}$ & $\mathrm{Y}$ \\
\hline 3 & $\mathrm{~N}$ & Y & Y & $\mathrm{Y}$ & 13 & $\mathrm{~N}$ & Y & $\mathrm{Y}$ & $\mathrm{N}$ \\
\hline 4 & $\mathrm{~N}$ & $\mathrm{Y}$ & $\mathrm{Y}$ & $\mathrm{Y}$ & 14 & $\mathrm{~N}$ & $Y$ & $\mathrm{Y}$ & $\mathrm{N}$ \\
\hline 5 & $\mathrm{Y}$ & $\mathrm{Y}$ & $\mathrm{Y}$ & $\mathrm{Y}$ & 15 & $\mathrm{~N}$ & $Y$ & $\mathrm{Y}$ & $\mathrm{Y}$ \\
\hline 6 & $\mathrm{Y}$ & $\mathrm{N}$ & $\mathrm{Y}$ & $\mathrm{N}$ & 16 & $\mathrm{~N}$ & $\mathrm{~N}$ & $\mathrm{~N}$ & $\mathrm{~N}$ \\
\hline 7 & $\mathrm{Y}$ & $\mathrm{N}$ & $\mathrm{Y}$ & $\mathrm{N}$ & 17 & $\mathrm{~N}$ & $\mathrm{~N}$ & $\mathrm{~N}$ & $\mathrm{~N}$ \\
\hline 8 & $\mathrm{Y}$ & $\mathrm{N}$ & Y & $\mathrm{Y}$ & 18 & $\mathrm{~N}$ & $\mathrm{~N}$ & $\mathrm{~N}$ & $\mathrm{~N}$ \\
\hline 9 & $\mathrm{Y}$ & $\mathrm{N}$ & $\mathrm{Y}$ & $Y$ & 19 & $\mathrm{~N}$ & $\mathrm{~N}$ & $\mathrm{~N}$ & $\mathrm{~N}$ \\
\hline 10 & $\mathrm{Y}$ & $\mathrm{N}$ & Y & Y & 20 & Y & $\mathrm{N}$ & $\mathrm{N}$ & $\mathrm{N}$ \\
\hline
\end{tabular}

\section{Summary}

In this paper, a fatigue state decision based on multi feature fuzzy fusion is proposed, which is based on the combination of two fuzzy controllers. The experimental results show that the combined use of eye and mouth features than using a single fatigue judgment accuracy is obviously improved, the correct rate of the algorithm proposed in this paper is in the head deflection fatigue test was $93.6 \%$, when the head deflection, the correct rate is $87.9 \%$ which can be known, this algorithm has higher detection rate.

\section{References}

[1]. Traffic Administration Bureau of the Ministry of public security, People's Republic of China road traffic accident statistics annual report , Ministry of Public Security Traffic Management Bureau, 2014

[2]. Klauer S G, Dingus T A, Neale V L, et al. The impact of driver inattention on near crash/crash risk: An analysis using the 100 car naturalistic driving study data, Washington: National Highway Traffic Safety Administration, 2006.

[3]. Liu C, and Subramanian R. Factors related to fatal singlevehicle run off road crashe, DOTHS811232, U.S. Department of Transportation, American National Highway Traffic Safety Administration, Washington, DC, USA, 2009.

[4]. Mac Lean A W, Davies D R T, \& Thiele K. The hazards and prevention of driving while sleepy, Sleep Medicine Reviews, 2003, 7: 507-521.

[5]. Ibrahim, Lamiaa Fattouh; Abulkhair, Maysoon; AlShomrani, Amal D; Al-Garni, Manal; Al-Mutiry, Ameerah; Al-Gamdi, Fadiah; Kalenen, Roa'a. Using Haar classifiers to detect driver fatigue and provide alerts, Multimedia Tools and Applications, 2014, 71(3):1857-1877. 